\title{
IDENTIFICACIÓN DE HONGOS FITOPATÓGENOS ASOCIADOS AL ROBLE (QUERCUS HUMBOLDTII BONPL.), EN LOS MUNICIPIOS DE ENCINO (SANTANDER), ARCABUCO, Y TIPACOQUE (BOYACÁ) ${ }^{1}$
}

\author{
Identification of phytopathogenic fungi associated with oak (Quercus humboldtii \\ Bonpl.), in the municipalities of Encino (Santander), Arcabuco and Tipacoque (Boyacá)
}

Palabras clave: filósfera, microorganismos antagonistas, Quercus humboldtii, rizosfera, suelo total.

Key words: phyllosphere, antagonistic microorganisms, Quercus humboldtii, rhizosphere, bulk soil.
Leidi Yunari Monroy Castro ${ }^{2}$

Luz Marina Lizarazo Forero ${ }^{3}$

\section{RESUMEN}

Los objetivos del presente estudio fueron aislar y determinar la presencia del patógeno Phytophthora ramorum y de otros posibles patógenos de Quercus humboldtii, y la posibilidad de utilizar la capacidad antagónica de bacterias aisladas de rizósfera y filosfera sobre estos. El estudio se realizó en la zona central del corredor de conservación Guantiva - La Rusia - Iguaque, en los municipios de Encino (Santander), Arcabuco y Tipacoque (Boyacá). Los aislamientos de los hongos fitopatógenos, se realizaron mediante siembra directa de hojas con sintomatología fúngica, en medios selectivos sólidos OGY, Sabouraud, y PDA + acido láctico al $0.2 \%$. Se utilizó la técnica de recuento en placa para el aislamiento de bacterias de suelo rizosférico y suelo total. No se aisló el hongo Phytophthora ramorum, pero si otros hongos fitopatógenos de los géneros Fusarium spp. y Pestalotia spp. Las poblaciones bacterianas de suelo rizosférico y suelo total fueron bajas y poco diversas, y dominadas por algunos morfotipos. Se identificaron cuatro especies de bacterias: Pseudomonas fluorescens, Bacillus macerans, Bacillus subtilis y Staphylococcus epidermidis. La comunidad de la filosfera estuvo dominada por Pseudomonas fluorescens. Los géneros Pseudomonas fluorescens y Bacillus subtilis, no mostraron propiedades antagónicas contra el hongo Pestalotia spp. Es indispensable realizar estudios adicionales, para confirmar si los géneros Fusarium spp. y Pestalotia spp., actúan como patógenos del Quercus humboldtii.

\begin{abstract}
The objectives of this study were to isolate and determine the presence of the pathogen Phytophthora ramorum and other potential pathogens of Quercus humboldtii, and evaluate the possibility of using the antagonistic capacity of bacteria isolated from rhizosphere and phyllosphere against them. The study was conducted in the conservation corridor Guantiva - La Rusia - Iguaque, in the municipalities of Encino (Santander), Arcabuco and Tipacoque (Boyacá). The phytopathogenic fungi were isolated using direct seeding of leaves with symptoms of fungal infection in OGY, Sabouraud, and PDA + Lactic acid at $0.2 \%$. We used the plate counting technique for the isolation of bacteria from rhizospheric and bulk soil. Phytophthora ramorum was not isolated, but phytopathogenic fungi of the
\end{abstract}

\footnotetext{
Trabajo enmarcado dentro del proyecto "Corredor de Conservación de Robles, una Estrategia para la Conservación y el Manejo Forestal en Colombia" Fundación MacArthur-Fundación Natura y DIN-UPTC.

Investigadora del Grupo de investigación Biología Ambiental. Universidad Pedagógica y Tecnológica de Colombia, Tunja, Boyacá.

Coordinadora Grupo de investigación Biología Ambiental, Universidad Pedagógica y Tecnológica de Colombia, Tunja, Boyacá. luz.lizarazo@ uptc.edu.co. Autor para correspondencia:
} 
genus Fusarium spp., and Pestalotia spp., were obtained in the isolates. Microbial populations of rhizospheric and bulk soil were scarce, exhibited low diversity, and were dominated by few morphotypes. We identified four species of bacteria: Pseudomonas fluorescens, Bacillus macerans, $\mathrm{Ba}$ cillus subtilis and Staphylococcus epidermidis. The phyllosphere community was dominated by $\mathrm{Pseu}$ domonas fluorescens. The species Pseudomonas fluorescens and Bacillus subtilis did not exhibited antagonistic properties against Pestalotia spp. Further studies are required to confirm Fusarium spp., and Pestalotia spp., pathogenic activity against Quercus humboldtii.

\section{INTRODUCCIÓN}

Los bosques de roble colombianos se encuentran compuestos por dos especies de la familia Fagaceae, el roble negro o morado (Colombobalanus excelsa Lozano et al. 1979), y el roble blanco o común (Quercus humboldtii Bonpl.). Estas dos especies adicionalmente son exclusivas de Colombia (Fundación Natura, 2000).

Quercus humboldtii se distribuye en las tres cordilleras de Colombia y en una localidad del Darién panameño. Cubre un rango altitudinal desde 1100 hasta $3450 \mathrm{~m}$ de altitud, con abundancia marcada en las laderas más secas, especialmente en la vertiente occidental de la Cordillera Oriental. En el Límite de los departamentos de Santander y Boyacá se encuentran los relictos de robles más extensos de Colombia. (Fundación Natura 2000, Solano 2002).

El hongo Phytophthora ramorum (Werres et al. 2001), provocó a partir del año 1995 mortalidad elevada entre las poblaciones de robles (Quercus), y especies del género Lithocarpus en la costa central de California, desde Monterey hasta el sur de Oregón. La enfermedad que ocasiona este hongo se denomina sudden oak death (SOD), muerte súbita del roble. Existen estudios recientes, que confirman que esta enfermedad ya se encuentra en el continente europeo, específicamente en Rumania y Bulgaria y otros países de la Comunidad Económica Europea (Rizzo et al. 2002, Rizzo \& Garbelotto 2003, Meentemeyer et al. 2004, McPherson et al. 2005, Brown \& Allen-Díaz 2009).
En árboles adultos el síntoma más evidente de la enfermedad, es la aparición de chancros sobre la corteza del tronco, en estas zonas se observan manchas cafés oscuro con exudados de savia. Las lesiones pueden presentarse desde el cuello de la planta hasta una altura de 20 metros (Jung et al. 2005, Balci et al. 2008).

Las bacterias además de incrementar el crecimiento de las plantas, también actúan como agentes de biocontrol de bacterias y hongos. Sus mecanismos de acción se centran en la producción de antibióticos y toxinas que reducen el crecimiento del patógeno y su potencial de infección (Handelsman \& Stabb 1996, Alexandrova et al. 2003, Chin-A-Weng et al. 2003). Competencia por el sitio de infección o nutrientes requeridos por el patógeno para penetrar al hospedero, parasitismo, inducción de enzimas extracelulares o de mecanismos de resistencia en las planta (Zhou \& Paulitz 1993, Dunne et al. 1997, Van Loon et al. 1998, De Meyer et al. 1999, Loper \& Henkels 1999, Yang \& Crowley 2000, Michaud et al. 2002).

El objetivo del presente estudio fue aislar e identificar hongos fitopatógenos, haciendo énfasis en la búsqueda de la especie Phytophthora ramorum, los cuales presumiblemente estarían afectando los bosques de robledales en algunos sectores de los municipios de Encino (Santander), Arcabuco y Tipacoque (Boyacá), y realizar pruebas de antagonismo con bacterias aisladas de la rizósfera y filosfera

\section{METODOLOGÍA}

\section{ÁREA DE ESTUDIO}

El proyecto se realizó en la zona central del corredor Guantiva - La Rusia - Iguaque, en los municipios de Encino (Santander), Arcabuco y Tipacoque (Boyacá).

Los robledales del Encino esta ubicados en un rango entre 1865 y $2535 \mathrm{~m}$ de altitud con geoformas rizadas a ondulantes y de cuestas escalonadas en las partes más altas. La temperatura promedio es de $18-14^{\circ} \mathrm{C}$ y presenta una pluviosidad de 1000 a $4000 \mathrm{~mm}$ anuales. En Arcabuco los robledales se 
localizan en la franja entre 2200 y 3100 m de altitud; el área se encuentra sobre escarpes, laderas desde rectas a irregulares con formas complejas, cóncavo convexas y longitudes desde cortas hasta largas y pendientes entre $17 \%$ y más del $100 \%$. Los suelos de esta área son de textura franco arenosa y franco arcillosos, con $\mathrm{pH}$ entre 4.0 y 4.6. El área de bosque de roble en el Parque Natural Municipal "Robledales de Tipacoque" (PNMRT), se encuentra ubicado en un paisaje de montaña conformado geológicamente por materiales originados a partir de rocas devónicas y paleozoicas. Comprende un rango altitudinal que va desde los 2800 a los $3300 \mathrm{~m}$. de altitud la precipitación calculada para el área de estudio es $1081.85 \mathrm{~mm} /$ año y la temperatura promedio de $17.4{ }^{\circ} \mathrm{C}$ (Solano et al. 2005).

\section{MUESTREO}

El área de muestreo se seleccionó de forma aleatoria dentro de los robledales de las tres áreas, tomando como criterio la búsqueda de árboles con los síntomas característicos de la enfermedad producida por Phytophthora ramorum: follaje amarillento, necrosis en el interior de la corteza que se manifiesta por un exudado de color rojo a negro viscoso, especialmente en la parte inferior del tronco. Al no encontrarse árboles con los anteriores síntomas, se determinó tomar muestras con otros síntomas presuntivos de enfermedades fúngicas (Figuras 1 y 2). En total se colectaron hojas con manchas color café, de diez árboles de Arcabuco y Tipacoque y de ocho árboles de Tipacoque. Las muestras de trozos de troncos de color negro, se tomaron de Arcabuco y Tipacoque. Solamente del municipio de Encino se recogieron unas muestras de semillas, las cuales presentaban manchas de color café. También se recogieron hojas sanas (árboles jóvenes y adultos), suelo rizosférico y de suelo total. La toma de muestra de la rizosfera se realizo de raíces de 3 árboles caídos. De cada uno de los individuos, se corto la raíz y se coloco en bolsas plásticas, posteriormente se sacudió la raíz y se separó el suelo adherido a ésta. Se recogieron tres muestras por árbol. A todas las muestras se le eliminaron los restos vegetales. Las muestras del suelo total (6 muestras por área de estudio), se tomaron a una profundidad de $10 \mathrm{~cm}$ alrededor del árbol, retirando previamente hojarasca. El tamaño de muestra fue de aproximadamente de $1 \mathrm{~kg}$. Todo el material colectado en bolsas plásticas estériles se llevó al laboratorio y se preservaron a $4^{\circ} \mathrm{C}$ hasta el momento de su análisis que no fue superior a $72 \mathrm{~h}$.

\section{AISLAMIENTO E IDENTIFICACIÓN DE HONGOS FITOPATÓGENOS}

Las hojas enfermas, los trozos de tronco y semillas se colocaron en cámara húmeda con papel filtro estéril, humedecido con agua destilada estéril y fueron mantenidas por siete a diez días con doce horas de luz y doce de oscuridad. Al mismo tiempo se realizaron siembras de hojas y trozos de troncos en cajas de Petri con el medio V8 agar suplementado con pimaricina $5 \mathrm{mg} / \mathrm{l}$, y rifampicina $25 \mathrm{mg} / \mathrm{l}$, Mansilla et al. (1993) y otros medios de cultivo selectivos OGY (Merck) ${ }^{\circledR}$, Sabouraud (Scharlau) ${ }^{\circledR}+$ Ácido Láctico al 0.2\%, Papa Dextrosa Agar (PDA - Scharlau ${ }^{\circledR}$ y Papa Dextrosa Agar (PDA) + Ácido Láctico al 0.2\%). Igualmente los crecimientos fungosos que se obtuvieron de la cámara húmeda se sembraron. Los medios de cultivo fueron incubados a una temperatura de $28^{\circ} \mathrm{C}$ durante 5-10 días. Los aislamientos obtenidos, en ambos casos, se clasificaron de acuerdo a sus características morfológicas con la ayuda de claves taxonómicas especializadas (Barnett \& Hunter 1972 ).

\section{RECUENTO DE MICROORGANISMOS DE LOS SUELOS RIZOSFÉRICOS Y SUELO TOTAL}

Se empleo el método de recuento en placa realizando diluciones seriadas en solución salina al $0.85 \%$, y siembras por triplicado en Agar Tripticasa Soya $(\text { ATS - Scharlau })^{\circledR}$. Las cajas fueron incubadas a $28^{\circ} \mathrm{C}$ y las unidades formadoras de colonias (UFC) se contaron a las 48 horas.

\section{AISLAMIENTO DE BACTERIAS FILOSFÉRICAS}

Tanto las hojas de árboles jóvenes como las adultas (por separado), fueron colocadas en una solución buffer (0.1 M fosfato de potasio, $\mathrm{pH}$ 7.0, peptona $0.1 \%$ ). Las células bacterianas fueron removidas por $7 \mathrm{~min}$ en un agitador a 120 r.p.m. $0.1 \mathrm{ml}$ de la muestra se sembró en medio King's B $(\mathrm{KB} \text { - Scharlau })^{\circledR}$ con cicloheximida (Scharlau) ${ }^{\circledR}$, para inhibir el crecimiento de hongos saprofíticos. 


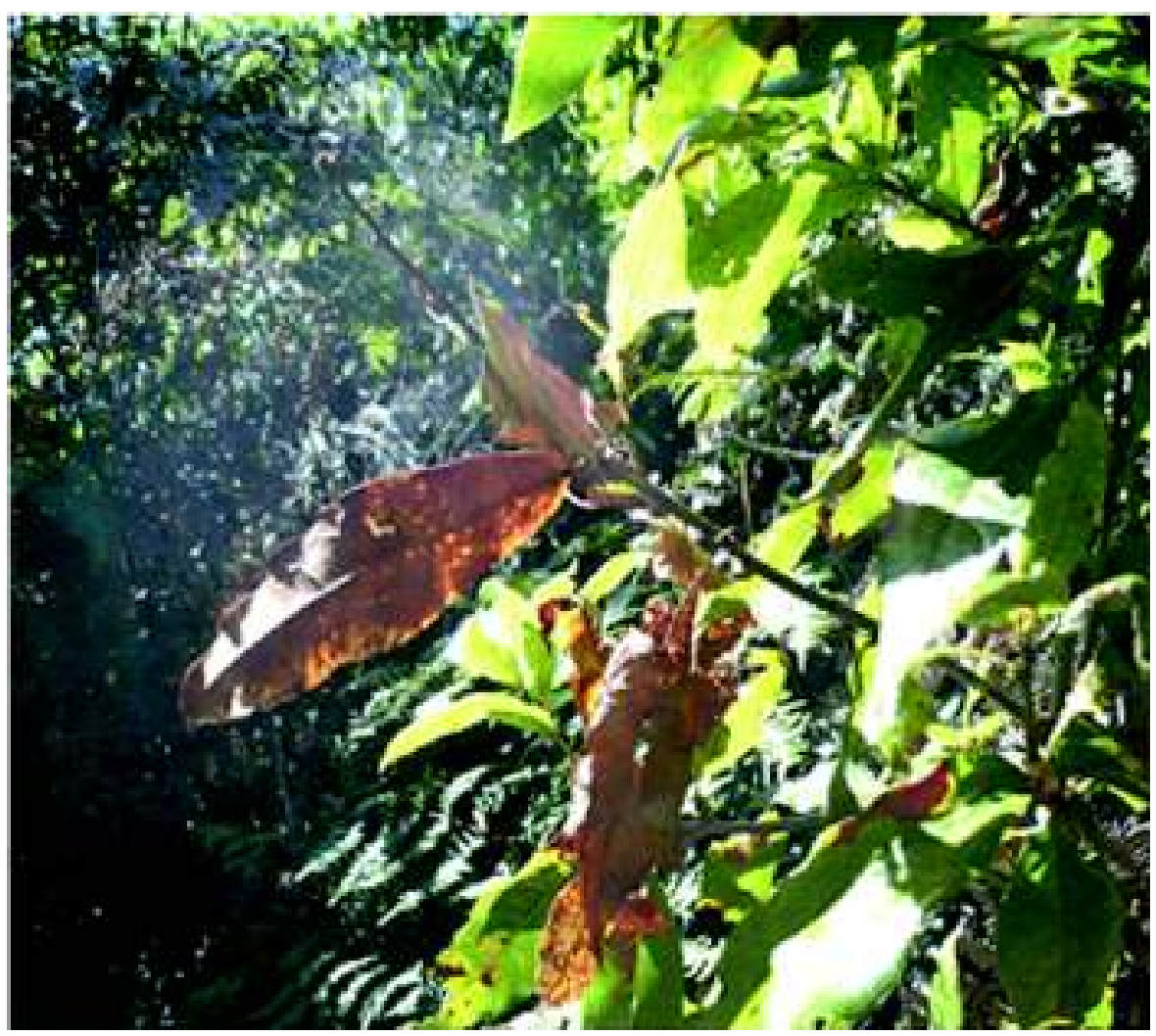

Figura 1. Hojas de roble con síntomas de infección fúngica (Fuente: Fausto Sáenz).

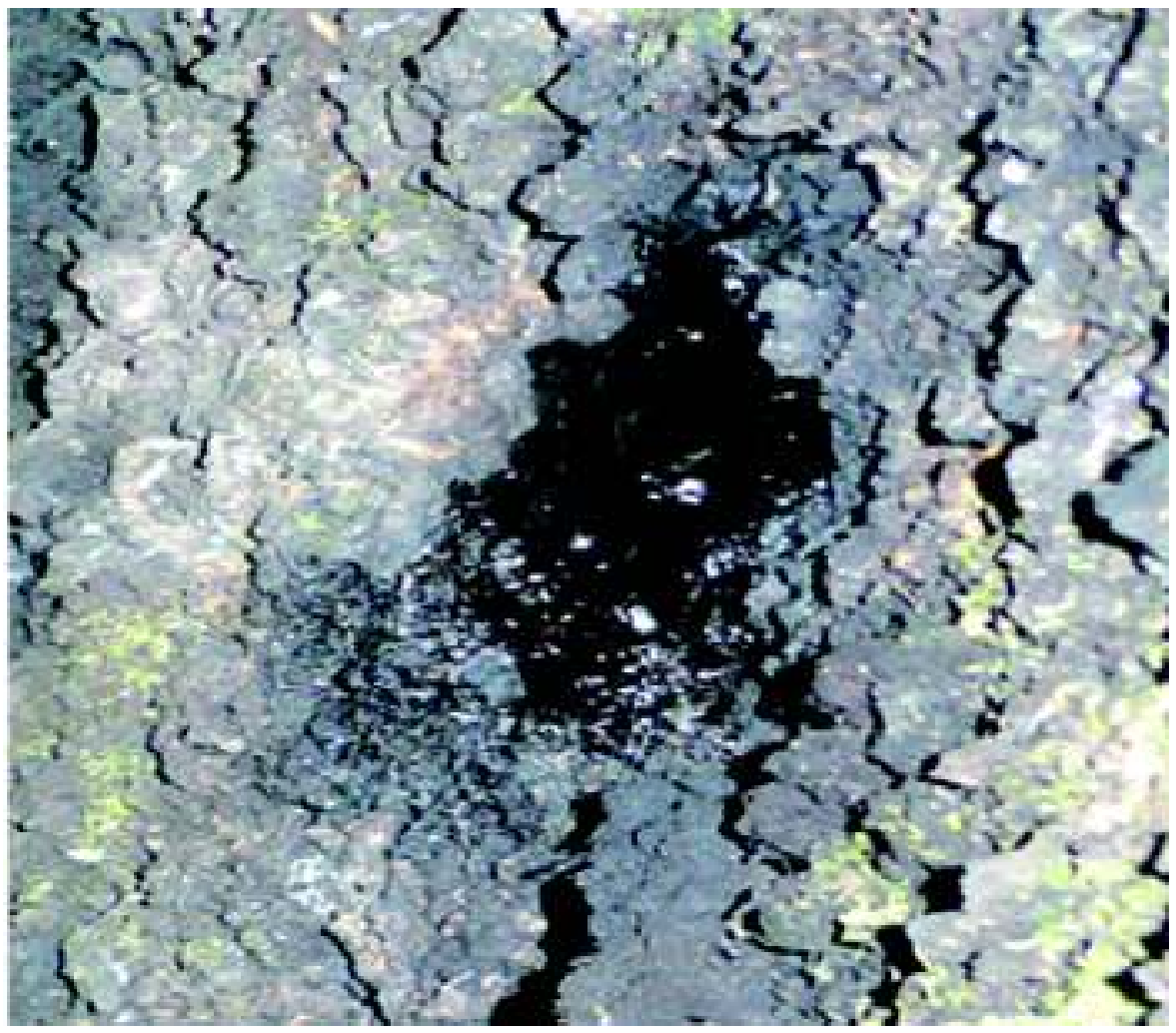

Figura 2. Tronco de roble con síntomas de infección fúngica (Fuente: Fausto Sáenz). 
Se incubó a una temperatura de $25{ }^{\circ} \mathrm{C}$ durante 96 horas (Thompsons et al. 1993).

Las colonias fueron descritas con base en la elevación, borde, aspecto, consistencia y color. Se tuvieron en cuenta las colonias pigmentadas y no pigmentadas.

Con el fin de determinar a qué géneros y/o especies pertenecían las bacterias que se aislaron de rizósfera, suelo total y filosfera, se realizaron pruebas bioquímicas API 20 E (para Enterobacterias-Biomérieux) ${ }^{\circledR}$ y API 20 NE (para no Enterobacterias- Biomérieux $)^{\circledR}$. También se realizaron pruebas bioquímicas tradicionales para algunos de los aislados.

\section{PRUEBAS DE ANTAGONISMO}

Se realizó la siembra por triplicado del hongo (Pestalotia spp.,) en Agar Papa Dextrosa (PDAScharlau $)^{\circledR}$, esto se incubó a una temperatura de $30^{\circ} \mathrm{C}$ durante 8 días, posteriormente se sembraron las bacterias a una concentración de $10^{6} \mathrm{UFC} / \mathrm{ml}^{8}$ (Pseudomonas fluorescens y Bacillus subtilis), en estrías horizontales, tanto en la parte superior como en la parte inferior del medio de cultivo para enfrentarlas al hongo, se incubó a una temperatura de $28^{\circ} \mathrm{C}$. El efecto antagónico se evaluó determinando el microorganismo que inhibió el crecimiento del otro (Páez et al. 2005).

\section{RESULTADOS}

\section{AISLAMIENTO E IDENTIFICACIÓN DE HONGOS FITOPATÓGENOS}

Se aislaron e identificaron los géneros Fusarium spp., Pestalotia spp., y otros tres géneros, tanto de hojas como de los trozos de troncos. En la tabla 1, se presentan los géneros determinados en cada uno de los tres sitios de muestreo. Ni en el medio V8 agar suplementado con antibióticos, que es especifico para el aislamiento de especies del género Phytophthora, ni en los demás medios selectivos en donde se sembraron las hojas con manchas café, trozos de corteza negros y semillas, se pudo aislar el hongo Phytophthora ramorum.

\section{AISLAMIENTO DE BACTERIAS DE SUELO RIZOSFÉRICO Y SUELO TOTAL}

El mayor promedio de bacterias totales fue obtenido de las muestras analizadas para suelo rizosférico y suelo total de los robledales de Encino (Tabla 2). Se lograron identificar los géneros Pseudomonas fluorescens de rizósfera de Tipacoque, Bacillus macerans de rizósfera y Bacillus subtilis y Pseudomonas fluorescens de suelo total de Arcabuco, y por último Staphylococcus epidermidis de suelo total de Encino.

Tabla 1. Hongos aislados de hojas y troncos según zona de estudio y síntomas.

\begin{tabular}{llll}
\hline LOCALIDAD & SÍNTOMAS & GÉNEROS & NÚMERO DE AISLADOS \\
\hline \multirow{2}{*}{ Encino } & Manchas Café & Pestalotia spp. & 2 \\
& Manchas Café & Penicillium spp. & 2 \\
\multirow{2}{*}{ Arcabuco } & Manchas Café & Pestalotia spp. & 1 \\
& Manchas Café & Fusarium spp. & 1 \\
& Manchas Negras & Penicillium spp. & 1 \\
Tipacoque & Manchas Café* & Alternaria spp. & 1 \\
& Manchas Café & Monilia spp. & 1 \\
\hline
\end{tabular}

*De muestras de hojas

**De muestras de trozos de tronco 
Identificación de hongos fitopatógenos asociados al roble (Quercus humboldtii Bonpl.), en los municipios de Encino (Santander)...

Tabla 2. Resultados del recuento en placa de suelo rizosférico y suelo total para las zonas de estudio

\begin{tabular}{ccc}
\hline LOCALIDAD & $\begin{array}{c}\text { SUELO RIZOSFÉRICO } \\
\text { UFC g-1 suelo* }\end{array}$ & $\begin{array}{c}\text { SUELO TOTAL } \\
\text { UFC g-1 suelo* }\end{array}$ \\
\hline Encino & $147 \times 10^{4}$ & $203 \times 10^{4}$ \\
Arcabuco & $95 \times 10^{4}$ & $2.28 \times 10^{4}$ \\
Tipacoque & $93 \times 10^{4}$ & $0.79 \times 10^{4}$ \\
\hline
\end{tabular}

*Valor promedio para los 6 muestreos analizados por área

\section{AISLAMIENTO DE BACTERIAS FILOSFÉRICAS}

Se logró aislar y determinar el género Pseudomonas fluorescens, tanto de hojas de árboles jóvenes como de adultos.

\section{PRUEBA DE ANTAGONISMO}

Estas pruebas dieron negativas, ya que las bacterias enfrentadas Bacillus subtilis y Pseudomonas fluorescens no lograron inhibir el crecimiento del hongo Pestalotia spp .

\section{DISCUSIÓN}

\section{AISLAMIENTO E IDENTIFICACIÓN DE HONGOS FITOPATÓGENOS}

De los cinco hongos aislados e identificados, solo Fusarium spp., y Pestalotia spp., se han documentado como fitopatógenos de plantas agrícolas y de otro tipo de forestales, causando grandes daños. $F u$ sarium spp., se ha asociado con la enfermedad de la pudrición de la corona de banano en diferentes partes del mundo (O’Donnell et al. 1998). Es uno de los hongos más frecuentemente encontrado en leguminosas y en la pos cosecha de varios cultivos, causando grandes pérdidas anuales a los productores de flores (Toledo et al. 2002). En general puede causar marchitamiento de las plantas de papa, de tomate y de otras solanáceas. Se ha identificado que las especies $F$. oxysporum, $F$. solanum, $F$. moniliforme, y otras, pueden ser capaces de ocasionar muerte en forestales y es común encontrar dos o tres especies actuando juntas (Kistler 1997).

Con relación a Pestalotia spp., Sosa de Castro et al. (2003), lo registran como causante de lesiones necróticas en plantas ornamentales, siendo la sintomatología característica de manchas de color castaño en las hojas, las cuales son muy similares a las observadas en las muestras de hojas que se tomaron de los robles de este estudio. Tal como se indico anteriormente, el género Pestalotia spp., no está reportado como fitopatógeno de los robles, aunque si para otros árboles forestales. Hay que destacar que a partir de las hojas con manchas café se aislaron Fusarium spp y Pestalotia spp., pero con mayor prevalencia este último.

En la bibliografía consultada se cita a Pestalotia spp., como patógeno de enfermedades en coníferas. El género Pestalotia funerea Desm var discolor Speg., es causante del marchitamiento y muerte de hojas y ramas jóvenes de Cupressus sempervirens var fastigiata en España. En Chile Pestalotia veronicae Herr., es promotor del tizón y caída de las acículas de Pinus radiata. También en ese país han determinado sobre Boldoea boldus, una nueva especie a la que se denominó Pestalotia matildae mujica. Se han observado plantas con muerte de porciones apicales de las ramas, la enfermedad comienza en la zona basal de los árboles y por la parte externa del follaje, y las partes muertas permanecen adheridas al árbol. En el tallo de las ramas afectadas se observan lesiones (cancros) que afectan a la corteza (González et al. 2002, Solano 1999). Adicionalmente se ha reportado la presencia de este patógeno en frutales en el rango altitudinal en que se pueden encontrar algunos robledales. Farfán et al. (2006), constataron que Pestalotia spp., es la causante de la "enfermedad de las costras o clavo del fruto de guayaba" y la severidad de la enfermedad fue mayor en el sistema guayaba $\mathrm{x}$ café, entre 1901 y $1960 \mathrm{~m}$ de altitud y en densidades superiores a 490 árboles por hectárea. 


\section{AISLAMIENTO DE BACTERIAS DE SUELO RIZOSFÉRICO Y SUELO TOTAL}

Se registraron valores promedios bajos de bacterias para suelos rizosféricos, pero se evidenció un menor tamaño poblacional para suelos totales, para las áreas de Arcabuco y Tipacoque. Se observó que las poblaciones son poco diversas y con una clara dominancia de un morfotipo/especie microbiana. Así de las muestras de rizosfera y suelo total, se logró aislar la especie Bacillus subtilis, la cual es considerada como una de las bacterias más eficientes para controlar enfermedades foliares, al igual que Pseudomonas fluorescens (Rodgers 1993, $\mathrm{Pa}-$ tkowska 2002, Kloepper et al. 2004). Con respecto a investigaciones en poblaciones rizosféricas en forestales, en estudios de bosques de pinos boreales, encontraron principalmente bacterias del orden Bacillales y proteobacterias asociadas a la micorrizósfera de micorizosfera (Timonen \& Hurek 2006, Bending et al. 2002).

\section{AISLAMIENTO DE BACTERIAS FILOSFÉRICAS}

El morfotipo predominante fue el género Pseudomonas fluorescens, bacteria con mecanismo de acción para el control biológico de microorganismos patógenos (Kong et al. 1997). El estudio de la filosfera se ha enfocado hacia la especies fitopatógenas de los géneros Pseudomonas, Xanthomonas y Erwinia. En particular hacia la Pseudomonas syringae, una especie que participa en las comunidades bacterianas filoesféricas como un patógeno, y como epifita (Morris et al. 1998, Wilson et al. 1999, Mercier \& Lindow 2000, Hirano \& Upper 2000).

\section{PRUEBA DE ANTAGONISMO}

El efecto de inhibición del crecimiento de Pestalotia spp. por Bacillus subtilis y Pseudomonas fluorescens fue negativo, a pesar de ser estas bacterias unas de las más eficientes en el control biológico de algunos patógenos. El género Pseudomonas, especialmente el grupo de las Pseudomonas fluorescentes y Bacillus subtilis, produce metabolitos secundarios con actividad antagónica y/o antibiótica contra varios patógenos rizosfericos (Ferrera \& Alarcón 2007). Entre estos metabolitos, están los sideróforos, inhibidores del crecimiento de varios hongos fitopatógenos, tales como Phytophthora parasitica (Seuk et al. 1988, Xiao \& Kisaalitaw 1998, Yang et al. 1994), Phythium ultimum (Hamdan et al. 1991) Fusarium oxysporum var. dianthi (Buysens et al. 1996 y Sclerotinia sclerotiorum (McLoughlin et al. 1992).

\section{CONCLUSIONES}

En ninguna de las tres poblaciones de robledales (Tipacoque, Arcabuco y Encino), monitoreadas, se constató ataque del género Phytophthora ramorum, a los árboles de roble (Quercus humboldtii), por lo que se puede afirmar que el agente patógeno no fue hallado en el presente estudio. No se encontró en las tres zonas monitoreadas sintomatología (aparición de chancros sobre la corteza del tronco, manchas marrón oscuro con exudados de savia) relacionada con Phytophthora ramorum.

Se aislaron Pestalotia spp., y Fusarium spp. El género Pestalotia ha sido asociado en Colombia con problemas fitosanitarios relevantes en frutales como la feijoa (Acca sellowiana Berg) y de guayaba (Psidium guajava L.), a altitudes de 1500-1900 m.s.n.m.

No se pudo demostrar que las especies Pseudomona fluorescens y Bacillus subtilis puedan actuar como agentes biocontroladores de Pestalotia spp.

\section{AGRADECIMIENTOS}

Las autoras del trabajo expresan un agradecimiento muy especial a la Fundación Natura y a la DIN de la UPTC, por el aporte de los recursos con los cuales se financiaron las diferentes actividades experimentales y para el logro de los objetivos propuestos. Al Biólogo Fausto Sáenz Jiménez, por su colaboración durante la fase de campo y fotos. Al Ingeniero Forestal Luis Mario Cárdenas por sus observaciones. Al fitopatólogo y profesor de la escuela de Biologia- UPTC Jorge Blanco, por su ayuda en la confirmación de los géneros fúngicos.

\section{REFERENCIAS BIBLIOGRÁFICAS}

Alexandrova, M. Bazzi, C. \& P. Lameri. 2003. Bacillus subtilis strain BS-F3: colonization of pear organs and its action as a biocontrol agent. Acta Horticulturae 590: 291-297. 
Balci, Y. Balci, S. Blair, J.E. Park, S-Y. Kang, S. \& W.L. Macdonald. 2008. Phytophthora quercetorum sp. nov., a novel species isolated from eastern and north-central USA oak forest soils. Mycological Research 1: 906-916.

Barnett, H. L. \& B. Hunter. 1972. Illustrated general of imperfect fungi. 4 ed. New York: Mc Millan Publishing Company. $241 \mathrm{p}$.

Bending, G. D., Poole, E. J., Whipps, J. M. \& D.J. Read. 2002. Characterization of bacteria from Pinus sylvestris-Suillus luteus mycorrhiza and their effects on root-fungus interactions and plant growth. FEMS Microbiology Ecology 39: 219-227.

Buysens, S., Heungens, K., Poppe, Y \& M. Jhofte. 1996. Involvement of Pyochelin and pioverdin in suppression of Pseudomonas aeruginosa 7NSK2. Applied and Environmental Microbiology 62: 865-871.

Brown, L. B. \& B. Allen-Diaz. 2009. Forest stand dynamics and sudden oak death: mortality in mixed-evergreen forests dominated by coast live oak. Forest Ecology and Management 257: 1271-1280

Chin-A-Weng, T. F. C., Bloenberg, G. V. \& B. J. J. Lugtenberg. 2003. Phenazines and their role in biocontrol by Pseudomonas bacteria. New Phytologist 57: 503-523.

De Meyer, G., Capieau, K., Audenaert, K., Buchala, A., Métraux, J. P. \& M. Hofte. 1999. Nanogram amounts of salicylic acid produced by the rhizobacterium Pseudomonas aeruginosa 7NSK2 activate the systemic acquired resistance pathway in bean. Molecular PlantMicrobe Interactions 12: 450-458.

Dunne, C., Crowley, Y., Moenne-Loccoz, D.N. Dowling, F.J. deBruijin, \& F. O'Hara. 1997. Biological control of Pythium ultimum by Stenotrophomonas malophilia W81 is mediated by an extracellular proteolytic activity. Microbiology 143: 3921-3931.

Farfán, P. D., Insuasty, O. \& F. Casierra. 2006. Distribución espacio temporal y daño ocasionado por Pestalotia spp. en frutos de guayaba. Revista Corpoica-Ciencia y Tecnología Agropecuaria 7: 89-98.
Ferrera, R. \& A. Alarcón. 2007. Microbiología agrícola: hongos, bacterias, micro y macrofauna, control biológico, planta-microorganismo. Ed. Trillas, México. 568 p.

Fundación Natura. 2000. Plan integral para la conservación biológica y el desarrollo sostenible en el municipio de Encino, Santander. Informe final preparado por la Alcaldía municipal de Encino y Fundación Natura.

Gonzalez, V. C. A., Seleme, F-V. \& C. M. Juri. 2002. Identificación del patógeno que causa el tizón de las coníferas en Catamarca. Universidad Nacional de Catamarca. Congreso Regional de Ciencia y Tecnología. Catamarca. Argentina. p. 7.

Hamdan, H., Weller, D. \& L. Thomashow. 1991. Relative importance of fluorescens siderophores and other factors in biological control of Gaeumannomyces graminis var. tritici by Pseudomonas fluorescens 2-79 and M4-80R. Applied and Environmental Microbiology 57: 3270-3277.

Handelsman, J. \& E. V. Stabb. 1996. Biocontrol of soilborne plant pathogens. Plant Cell 8: 1855-1869.

Hirano, S. S. \& CH. D. Upper. 2000. Bacteria in the leaf ecosystem with emphasis on Pseudomonas syringaea pathogen, ice nucleus and epiphyte. Microbiology and Molecular Biology Reviews 64: 624-653.

Jung, T., Hudler, G.W., Jensen-Tracy, S. L., Griffiths, H. M., Fleischmann, F. \& W. Osswald. 2005. Involvement of Phytophthora species in the decline of European beech in Europe and the USA. Mycologist 19: 159-166.

Kistler, H. C. 1997. Genetic diversity in the plantpathogenic fungus Fusarium oxysporum. Phytopathology 87: 474-479.

Kong, G. A., Kochman, J. K. \& J. F. Brown. 1997. Phylloplane bacteria antagonistic to the sunflower pathogen Alternaria helianthi. Australasian Plant Pathology 26: 85-97.

Kloepper, J. W., Ryu, Ch. \& S. Zhang. 2004. The nature and application of biocontrol microbes: Bacillus spp.-induced systemic resistance and promotion of plant growth by Bacillus spp. Phytopathology 94: 259-1266. 
Loper, J. E. \& J. S. Henkels. 1999. Utilization of heterologous siderophores enhances levels of iron available to Pseudomonas putida in the rhizosphere. Applied Environmental Microbiology 65: 5357-53-63.

Lozano, C. G., Hernández, C. J . I. \& S. J. E. Henao. 1979. Hallazgo del género Trigonobalanus Forman en el Neotrópico. Caldasia 112: 517-537

Mansilla, J. P., Pintos, C. \& M.C. Salinero. 1993. Aislamiento e identificación en la provincia de Pontevedra de Phytophtora cinnamoni Rands como patógeno de la viña. Boletín de Sanidad Vegetal Plagas 19: 545-549.

Meentemeyer, R., Rizzo, D. M., Mark, W. \& E. Lotz. 2004. Mapping the risk of establishment and spread of sudden oak death in California. Forest Ecology and Management 200: 195-214.

Mercier, J. \& S. E. Lindow. 2000. Role of leaf surface sugars in colonization of plants by bacterial epiphytes. Applied Environmental Microbiology 66: 369-374.

Michaud, M., Martinez, C., Simao-Beaunir, A. M., Belander, R. R. \& R. J. Tweddell. 2002. Selection of antagonist microorganisms against Helminthosporium solani, causal agente of potato silver scurf. Plant Disease 86: 717-720.

Morris, C.E., Monier, J-M. \& M-A. Jacques. 1998. A technique to quantify the population size and composition of the biofilm component in communities of bacteria in the phyllosphere. Applied and Environmental Microbiology 64: 4789-4795.

McLoughlin, T. J., Quinn, J. P., Bettermann, A. \& R. Bookland. 1992. Pseudomonas cepacia suppression of sunflower Pseudomonas cepacia Wilt fungus and role of anti-fungal compounds in controlling the disease. Applied and Environmental Microbiology 58: 1760-1763.

McPherson, B.A., Mori, S. R., Wood, D. L., Storer, A. J. Svihra, P. Kelly, N. M. \& R. B. Standiford. 2005. Sudden oak death in California: Disease progression in oaks and tanoaks. Forest Ecology and Management 213: 71-89.
O’Donnell, K., Kistler, H. C., Cigelnik, E. \& R. C. Ploetz. 1998. Multiple evolutionary origins of the fungus causing Panama disease of banana: concordant evidence from nuclear and mitochondrial gene genealogies. Proceedings of National Academy Sciences 95: 2044-2049.

Páez, M., Martínez-Nieto, P. \& J. Bernal-Castillo. 2005. Siderophore producing Pseudomonas as pathogenic Rhizoctonia solani and Botrytis cinerea antagonists. Universitas Scientiarum 10: 65-74.

Patkowska, E. 2002. The role of rhizosphere antagonistic microorganisms in limiting the infection of underground parts of spring wheat. Electronic Journal of Polish Agricultural Universities 5(2): 1-9.

Rizzo, D. M., Garbelotto, M., Davidson, J. M., Slaughter, G. W. \& S. T. Koike. 2002. Phytophthora ramorum as the cause of extensive mortality of Quercus spp. and Lithocarpus densiflorus in California. Plant Disease 86: 205-214.

Rizzo, D. M. \& M. Garbelotto. 2003. Sudden oak death: endangering California and Oregon forest ecosystems. Frontiers in Ecology and Management 1: 197-204.

Rodgers, P. B. 1993. Potential of biopesticides in agriculture. Pesticide Science 39:117-129.

Seuk, C., Paulita, T. \& R. Baker. 1988. Attributes associate with increased bio-control activity of fluorescent Pseudomonas. Journal of Plant Pathology 4: 218-225.

Solano, C. 2002. Paisaje productivo sostenible para el mejoramiento de la calidad de vida de los pobladores rurales y la conservación de los bosques de roble y ecosistemas asociados en los municipios de Encino, Coromoro (Santander) y Belén (Boyacá). Fundación Natura. Bogotá.

Solano, C., Roa, C. \& Z. Calle. 2005. Estrategia de desarrollo sostenible. Corredor de conservación Guantiva-La Rusia-Iguaque. BoyacáSantander/Colombia. Colombia: Fundación Natura-The Nature Conservancy. 92 p.

Solano, L. 1999. Efecto del embolsado del fruto sobre la incidencia de Pestalotia versicolor Speg. Producción y calidad en dos variedades de guayaba Psidium guajava L. Trabajo de grado 
(Ingeniero Agrónomo). Universidad Pedagógica y Tecnológica de Colombia-UPTC. Facultad de Ciencias Agropecuarias. Escuela de Ingeniería Agronómica. UPTC. Tunja. 91 p.

Sosa de Castro, N. T. Álvarez, R. E. \& M. G. Cabrera. 2003. Ocurrencia de Pestalotia sp. causando lesiones necróticas en plantas de Jazmín del Cabo (Gardenia Augusta). Universidad Nacional del Nordeste. Comunicaciones Científicas y Tecnológicas. Corrientes. Argentina. 3p.

Timonen, S. \& T. Hurek. 2006. Characterization of culturable bacterial populations associating with Pinus sylvestris-Suillus bovines mycorrhizospheres. Canadian Journal of Microbiology 52: 769-778.

Toledo, Y., Hernández, A. \& M. Álvarez. 2002. Determinación del efecto antagónico de un biopreparado a partir de una cepa de Burkholderia cepacia ante Fusarium sp en un cultivo de Gladiolo (Gladiolus sp). Departamento de Biofertilizantes y Nutrición de las Plantas, Instituto Nacional de Ciencias Agrícolas. La Habana, Cuba. Cultivos Tropicales 23:11-15.

Thompsons, I. P., Baley, M. J., Fenlon, J. S., Fermor, T. R., Lilley, A. K., Lynch, J. M., McCormack, P. J., McQuilken, M. P., Purdy, K. J., Rainey, P. B. \& J.M. Whipps. 1993. Quantitative and qualitative seasonal changes in the microbial community from the phyllosphere of sugar beet (Beta vulgaris). Plant and Soil 150: 177-191.

Van Loon, L. C., Bakker, P. A. H. M. \& C. M. J. Pieterse. 1998. Systemic resistance induced by rhizosphere bacteria. Annual Review of Phytopathology 36: 453-483.
Werres, S., Marwitz, R., Man In'tVeld, W. A., De Cock, A. W . A. M., Bonants, P. J. M., De Weerdt, M., Themann, K., Ilieva, E. \& R.P. Baayen. 2001. Phytophthora ramorum sp. nov., a new pathogen on Rhododendron and $\mathrm{Vi}$ burnum. Mycological Research 105: 1155-116.

Wilson, M., Hirano, S. S. \& S. E., Lindow. 1999. Location and survival of leaf-associated bacteria in relation to pathogenicity and potential for growth within the leaf. Applied and Environmental Microbiology 65: 1435-1443.

Xiao, R. \& W. Kisaalitaw. 1998. Fluorescent pseudomonad pyoverdines bind and oxidize ferrous ion. App1ied and Environmental Microbiology 54: 1472-1476.

Yang, C. H. \& D. E. Crowley. 2000. Rhizosphere microbial community structure in relation to root location and plant iron nutritional status. Applied Environmental Microbiolology 66: 345-351.

Yang, C. H., Menge, J. \& D. Cooksey. 1994. Mutations affecting hyphal colonization and Pyoverdine production in pseudomonads antagonistic toward Phytopthora parasitica. Applied and Environmental Microbiology 60: 473-481.

Zhou, T. \& T. C. Paulitz. 1993. In vitro and in vivo effects of Pseudomonas spp. on Pythium aphanidermatum: Zoospore behavior in exudates and on the rizoplane of bacteria-treated cucumber roots. Phytophatology 83: 872-876. 